\title{
Electricity Generation in Microbial Fuel Cell (MFC) by Bacterium Isolated from Rice Paddy Field Soil
}

\author{
Fakhriah Fakhirruddin ${ }^{1}$, Azura Amid ${ }^{1}$, Wan Wardatul Amani Wan Salim ${ }^{1}$, and Azlin \\ Suhaida Azmi ${ }^{*}$ \\ ${ }^{1}$ Department of Biotechnology Engineering, Faculty of Engineering, International Islamic University \\ Malaysia (IIUM), P.O. Box 10, 50728 Kuala Lumpur, Malaysia
}

\begin{abstract}
Microbial fuel cell (MFC) is an alternative approach in generating renewable energy by utilising bacteria that will oxidize organic or inorganic substrates, producing electrons yielded as electrical energy. Different species of exoelectrogenic bacteria capable of generating significant amount of electricity in MFC has been identified, using various organic compounds for fuel. Soil sample taken from rice paddy field is proven to contain exoelectrogenic bacteria, thus electricity generation using mixed culture originally found in the soil, and pure culture isolated from the soil is studied. This research will isolate the exoelectrogenic bacterial species in the rice paddy field soil responsible for energy generation. Growth of bacteria isolated from the MFC is observed by measuring the optical density (OD), cell density weight (CDW) and viable cell count. Mixed bacterial species found in paddy field soil generates maximum power of $77.62 \mu \mathrm{W}$ and $0.70 \mathrm{~mA}$ of current. In addition, the research also shows that the pure bacterium in rice paddy field soil can produce maximum power and current at $51.32 \mu \mathrm{W}$ and $0.28 \mathrm{~mA}$ respectively.
\end{abstract}

\section{Introduction}

Microbial Fuel Cell (MFC) is a device, which enables generation of electricity by exploiting bacterial action in metabolizing organic or inorganic substrate under anaerobic condition. The breakdown of the process occurring is that in the anodic chamber, substrate is oxidized by bacteria, producing electrons that are transferred to anode electrode. Transfer of electrons is mediated either by membrane-associated components or soluble electron shuttle. The electrons will then be further transported to the cathode via resistor. Subsequently, current is generated by the positive terminal and flows to the anode, in contrast to the direction of electron flow $[1,2]$. Energy generated from MFC is typically evaluated in the form of maximum power density and is renewable and safe for environment. There are several designs of MFC currently being used, the single chamber MFC, dual or two chambers MFC and triple chambers MFC [3]. Single chamber MFC

\footnotetext{
*Corresponding author: azlinsu76@,iium.edu.my
} 
contains only one vessel residing both anode and cathode electrodes. Substrate is filled into the vessel, sandwiched between the two electrodes.

Bacteria responsible in powering up the MFCs are specifically termed exoelectrogens, microorganisms capable of generating and transferring electrons extracellularly [4-6]. Various substrates/ fuels are utilised by exoelectrogens in an MFC, ranging from simple molecules to complex substrates containing different types of organic matter such as wastes and soil [7]. Several exoelectrogenic bacteria species have been successfully isolated from paddy field soil as presented by research from [8]. Denaturing gradient gel electrophoresis (DGGE) of polymerase chain reaction (PCR)-amplified gene fragments was employed for identification of bacterial species residing on the anode and cathode of the MFC. Through database search of the bacteria profiles, several species of bacteria were identified and among them, one of the strains was a close relative to Natronocella acetinitrilica (accession number EF103127, 96\% identical in nucleotide sequence). Other than that, strains closely related to uncultured Beijerinckiaceae bacterium clone GASP-38KB-490-B06 (EU044137, 97\%), Rhizobiales bacterium A48 (AB081581, 96\%), and Rhodobacter gluconicum (DQ363135, 99\%) were also identified. These bacterial strains were responsible in electricity generation of MFC fed with rice paddy field soil [8].

In another research [9], bacterial species closely related with Acetobacterium sp. HAAP 1 (98\% identical) from the phylum Firmicutes was the dominant species identified an aircathode MFC. The MFC utilised rice paddy field soil as substrate cum inoculum and the identification was made through $16 \mathrm{~S}$ rRNA identification method. The dominancy was then followed by a relative of Firmicutes bacterium BV9-3a (94\% identical) and strain related to Holophage foetida (89\% identical) [9]. Further, close relative of bacterial strain Geobacter sulfurreducens PCA (AE017180) with 99.53\% identity (named active strain D-8) was also identified in research [10]. Geobacter sulfurreducens is a known exoelectrogenic species with high efficiency in generating electricity and has been isolated from various environment such as freshwater and lotus field mud [11]. Relative of G. sulfurreducens isolated from paddy field soil can generate electricity better (i.e. 1.5 times higher current density) than the predecessor (i.e. G. sulfurreducens PCA). Strain D-8 could generate up to $1088 \pm 7.7 \mu \mathrm{A} / \mathrm{cm}^{2}$ whilst $G$. sulfurreducens PCA was only capable of producing current density at highest $722 \pm 2.6 \mu \mathrm{A} / \mathrm{cm}^{2}[10]$.

Bacteria associated with the rhizosphere of paddy plant can also produce electricity. Kouzuma et al. [12] analysed the microbiomes present at anodes of the MFCs set-up in paddy field through pyrotag sequencing and 16S rRNA method. Additionally, two MFC set-ups with paddy field soil as substrate were fed with acetate and glucose and a comparative analysis was made between the three (i.e. rhizosphere MFC, acetate-fed MFC, glucose-fed MFC). For control, bulk soil was also sampled for microbial identification. Bacteria from genus Geobacter were identified and were more prominently discovered in the anodes of MFCs rather than in bulk soil. The findings confirmed that Geobacter was responsible for the electricity production in MFC. Different strains were in abundance in different MFCs. G. psychropillus was identified as the main exoelectrogen present in glucose-fed MFC and rhizophere MFC, whereas G. sulfurreducens was more abundant in acetate-fed MFC [12].

Rice is a staple food in a lot of South Asian countries including Malaysia and Japan has been doing multiple researches on MFC with rice paddy field soil as substrate. Mirroring the effort by the Japanese, and with the abundance of rice paddy field soil in Malaysia, research combining MFC and rice paddy field soil seems to be promising. Currently, there are no researches on MFC utilising rice paddy field soil in Malaysia and the absence of similar researches creates a unique opportunity in creating novel research in this country. Additionally, the optimum temperature for all growth stages of rice is in between $18-40^{\circ} \mathrm{C}$, a temperature fit of Malaysian weather for the execution of the research [13]. In [14], five 
samples of paddy field soil with different chemical properties were collected to study the effect of soil condition in electricity generation from MFC. Upon investigation, soil with higher dissolved organic compound (DOC) and ammonium $\left(\mathrm{NH}_{4}^{+}\right)$content could generate more electricity than the other soil samples [14].

In the present study, a single chamber MFC was prepared with rice paddy field soil as both inoculum and substrate to study the electricity generation by the microbiota present in the soil. A species of exoelectrogenic bacterium was isolated from the mixed microbiota and its capability in generating electricity was observed. The isolated bacterium species is to be identified for further researches on the mechanism of electron transfer and substrate uptake of the bacteria. The results suggested that mixed culture produced more electricity as compared to pure culture inoculated in the paddy field soil.

\section{Materials and methods}

\subsection{MFC configuration}

Single chambered MudWatt MFC purchased from KeegoTech, USA was used throughout the research. The anode and cathode were made up of graphite fibre felt with thickness of $0.5 \mathrm{~cm}$ and diameter of $8 \mathrm{~cm}$ and $1 \mathrm{~cm}$ thickness with diameter of $8.5 \mathrm{~cm}$, respectively. Both anode and cathode electrodes were connected to a titanium wire of $22.9 \mathrm{~cm}$ and 19.1 $\mathrm{cm}$ respectively. The MFC vessel was made from plastic materials, and could accommodate up to $400 \mathrm{~mL}$ (equivalent to $400 \mathrm{~cm}^{3}$ ) of water/liquid feed. Blinker board with $10 \mu \mathrm{F}$ capacitor and light emitting diode (LED) was linked with the end of titanium wires connecting to anode and cathode electrodes. The temperature was fixed to room temperature $\left(27^{\circ} \mathrm{C}\right)$ at all time, by placing the MFC at designated place in the laboratory of International Islamic University Malaysia (IIUM).

\subsection{Feed and inoculum}

Rice paddy field soil was taken from paddy field in Sungai Limau, Kedah Malaysia. The MFC vessel was filled with $342.9 \mathrm{~g}$ of the paddy field soil that acted as the substrate and also the inoculum from where the bacteria were isolated. The paddy field soil was packed in a very saturated manner to prevent air bubbles formation, especially at anode for no oxygen should be present in this area. Presence of oxygen at anode was undesirable and precautions were taken to prevent oxygen from disturbing with normal MFC function.

\subsection{Experimental designs and operation}

\subsubsection{Generation of electricity and application of resistor}

As the LED blinking stabilised (i.e. blinking at similar intervals consistently), the electricity generated by the MFC was measured using two methods. The first method is using Mudwatt explorer application provided by KeegoTech and the second method using resistor of values $47,100,220,470,1000,2200$ and $4700 \Omega$.

\subsubsection{Isolation of bacteria from soil sample}

The bacterial species present at anode electrode and responsible for powering up the MFC were isolated in petri dish. LED that was connected to the blinker board of the MFC must 
be blinking at the time of isolation, to ensure the presence of exoelectrogenic bacteria. The MFC was disassembled to reach for the anode, and the anode graphite felt was rinsed with sterile distilled water. Sterilised cotton bud was used to swap the surface of anode graphite felt and diluted in $10 \mu \mathrm{L}$ of sterile distilled water. Subsequently, the cotton bud was spread on pre-prepared nutrient agar. Single colonies of bacterial species formed after 24 hours of incubation time on the agar and a colony was transferred to a different agar plate. The steps were repeated until pure culture/colony was obtained. The isolation was performed under sterile condition to avoid contamination of other bacteria aside from the exoelectrogenic bacteria.

Nutrient broth was also prepared as medium for growth of the unidentified bacterial species from rice paddy field soil. When only a pure colony of a single species of bacteria was obtained on agar, the bacterium was then inoculated in $7 \mathrm{~mL}$ of nutrient broth and was left overnight. The overnight culture (containing the desired bacteria) was then mixed with $28 \mathrm{~mL}$ of nutrient broth medium. The inoculation was done with $20 \%$ cell to $80 \%$ nutrient broth percentage, and the experiment was done in triplicates.

\subsubsection{Optical Density (OD) measurement of growth of bacteria isolated from anode of MFC}

Growth of the bacteria in broth was observed and measured hourly (until $8^{\text {th }}$ hour) and daily for seven days using spectrophotometer at $600 \mathrm{~nm}$ wavelength. Immediately after inoculation, $1.5 \mathrm{~mL}$ of the bacteria cultured in nutrient broth was transferred into a $3 \mathrm{~mL}$ cuvette and had the $\mathrm{OD}_{600}$ read, and continued at every 30 minutes interval for eight hours. Nutrient broth was used as blank. Based on the OD readings, the doubling time $\left(t_{d}\right)$ for the growth of bacteria was calculated.

\subsubsection{Cell Dry Weight (CDW) measurement}

The CDW was measured to obtain biomass reading of the bacterial culture. Three aluminium weighing boat were prepared and dried overnight in the oven. The initial weight of the three aluminium boats were recorded upon overnight drying (M1). $1 \mathrm{~mL}$ of bacterial culture was transferred into microcentrifuge tube and centrifuged for 30 minutes at 5000 rpm. After 30 minutes, pellet formation was observed on the microcentrifuge tubes. If pellet formed, the supernatant was to be discarded and $1 \mathrm{~mL}$ of distilled water was used to resuspend the pellet before the liquid was poured into aluminium weighing boat. If no pellet was formed, the supernatant was poured directly into the aluminium weighing boat. The weighing boats were left overnight in the oven for drying, and the final weight was recorded (M2). The DCW (in $\mathrm{g} / \mathrm{mL}$ ) was calculated using equation (1):

$$
\text { Dry Cell Weight }\left(\frac{g}{m L}\right)=\frac{[M 2(g)-M 1(g)]}{1 m L}
$$

\subsubsection{Viable cell count using Hemocytometer}

\subsubsection{Bacterial suspension preparation}

Tube containing bacterial culture was swirled to ensure even distribution of bacteria concentration across the tube. $100 \mu \mathrm{L}$ of suspension from the tube was transferred to a sterilised microcentrifuge tube using sterile pipette. $100 \mu \mathrm{L}$ of trypan blue solution was then immediately transferred to the same microcentrifuge tube containing bacterial culture. Mixing was done by pipetting the suspension in the tube up and down. 


\subsubsection{Viewing with compound light microscope}

After proper mixing of the suspension with trypan blue solution, sufficient amount of suspension was transferred to hemocytometer and let to seep through under the cover slip via capillary action. The suspension was viewed under compound light microscope at $40 \mathrm{x}$ magnification. Total number of cells in five squares of the hemocytometer was counted and using equation (2), the viable cell count was calculated;

$$
=\frac{\sum \text { number of cells in five squares } \times 1000 \times \text { dilution factor }(\text { ie: } 2)}{\text { number of squares }(\text { ie: } 5) \times 0.004 \mathrm{~mm}^{3}}
$$

\subsubsection{Inoculation of exoelectrogenic bacterium species into soil}

Soil sample was sterilised at $121^{\circ} \mathrm{C}$ for 30 minutes, twice in 48 hours interval [15] and the MFC chamber was exposed to UV light for the purpose of killing all bacteria present. Pure bacterial culture initially prepared in nutrient broth was mixed with the soil after 8-16 hours growth in the broth. The relevant behind this action is that the growth of bacteria is potentially at exponential phase at period 8-16 hours. After 8-16 hours, $8.6 \mathrm{~mL}$ of preprepared culture was mixed evenly with sterilised soil sample using spatula [16].

\section{Results and discussions}

\subsection{Isolation of bacteria in nutrient agar}

\subsubsection{Isolation and growth in petri dish}

As a result of isolation of bacteria residing on anode, two major colonies were observed (Fig.1). The two colonies differ in sizes with one colony (labelled as 1 in Fig.1) was significantly smaller than the colony labelled 2 . A single colony of 1 and 2 were further streaked, and colony 2 did not grow well on nutrient agar. Growth of colony 2 on nutrient agar plate halted at $8^{\text {th }}$ hour after streaking, hence colony 2 was not considered for inoculation in pure culture MFC. A single colony from colony 1 was also further streaked (Fig.2) and the morphology matched with the original small single colony isolated from anode from Fig

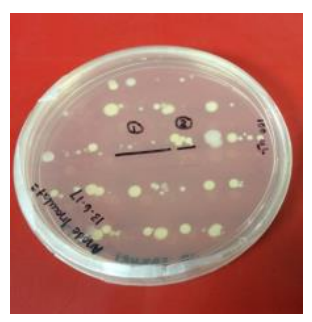

Fig. 1: Isolation of bacteria at anode.

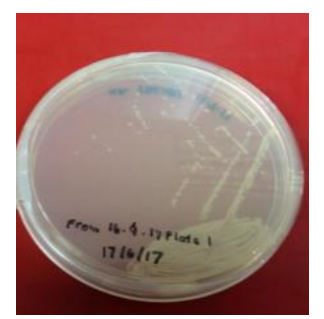

Fig. 2: Pure culture streak.

\subsection{Growth of pure/isolated bacteria in nutrient medium}

\subsubsection{OD reading}

Growth of bacteria isolated from anode of MFC was observed through OD reading at 600 $\mathrm{nm}$ wavelength for seven days, and at every 30 minutes interval for the first eight hour. The 
exact species of the bacteria isolated were unknown, hence $600 \mathrm{~nm}$ wavelength was chosen based on literature provided in [17]. The experiment was done and the average growth (depicted as $\ln (\mathrm{OD})$ ) from triplicates of the bacteria was shown in Fig. 3. The $\mathrm{OD}_{600}$ reading increased rapidly within the 8 hours of inoculation, and steadily on day 2 onwards, and declined on day 7. The growth pattern of the isolated microorganism was similar to the typical growth pattern of bacteria, confirming the microorganism isolated to be bacteria. Since the aim of the study was to investigate electricity generation by pure monoculture isolated from rice paddy field soil, the characterisation of the bacterial species present was essential. Therefore, the isolated bacteria were grown outside the soil environment to observe the behaviour and characteristics (i.e. morphology of the cell, etc) for comparison and validation with the behaviour of bacterial cells in the soil.

From graph plotting, value of $\mu$ was found out to be $0.004 \mathrm{~min}^{-1}$, and the doubling time was calculated to be 173.3 minutes or equivalent to 2.9 hours (Fig. 3). Growth of bacteria was at exponential phase on the first day of inoculation, therefore for pure culture MFC setup, the bacteria were inoculated in nutrient broth for five hours (300 minutes) prior to being inoculated into the sterilised paddy field soil. Since the doubling time is at the $173^{\text {th }}$ minutes, pure bacteria were inoculated for five hours to ensure decent bacteria concentration exist to power up the MFC when the bacteria were inoculated into the soil. The highest $\mathrm{OD}_{600}$ reading (average of three replicates) recorded was on day 6 , and started to decline on day 7 . The decline in $\mathrm{OD}_{600}$ reading indicated death phase for the bacteria.

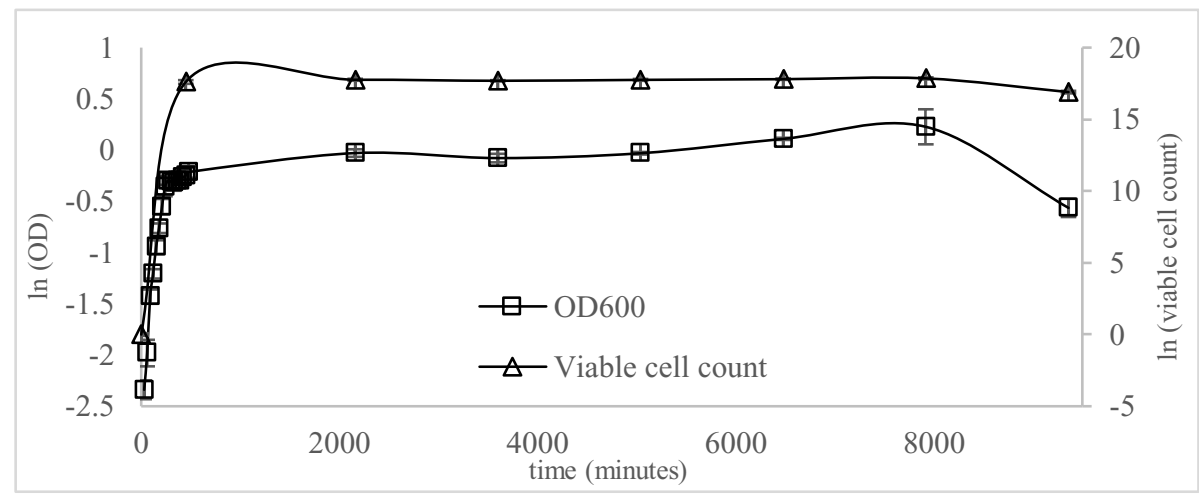

Fig. 3. Growth of bacteria observed as $\ln \left(\mathrm{OD}_{600}\right)$ and $\ln$ (viable cell count).

\subsubsection{Viable cell count}

Total viable cells were calculated every day (i.e. 7 days) based on the protocol mentioned in 2.3.5.2. Total viable cell counts were the highest on day 6 , based on the average taken from triplicates (Fig. 3). Data collected from total viable cell count protocol matched with the $\mathrm{OD}_{600}$ data shown in section 3.2.1, further confirming that the bacteria will enter death phase on day 7 and is at exponential growth on the first eight hours of day 1, hence inoculation of isolated bacteria into soil for pure culture MFC needed to be done before the growth curve declined. Further, the viable cell counts data ruled out the relevancy of carrying cell dry weight protocol on the isolated bacteria. CDW is informative only if the cell count of microorganism is more or equal to $10^{9}$ [18]. Since the viable cell counts from the triplicates are all lesser than $10^{9}$ (i.e. maximum cell counts are at $10^{7}$ ) CDW values are not relevant. 


\subsection{Electricity generation by mixed and pure culture}

In this experiment, power generated by mixed culture of exoelectrogenic bacteria and pure exoelectrogenic bacterium species were compared over a period of 30 days. The unknown microbiota residing in anode of the MFC produced up to $27 \mu \mathrm{W}$ of power on day 14 . Power generated from mixed culture MFC was relatively stable until $24^{\text {th }}$ day. However, a decline was observed from day 24 onwards, presumably due to reduction of substrate available (Fig.4). Similarly, pure culture inoculated in the soil generated highest power output on day 13 , at $24 \mu \mathrm{W}$ before decreasing and stabilising at $22 \mu \mathrm{W}$ from day 14 onwards. Decrease of power generated was observed starting on day 27 onwards (Fig. 4). Limitation of substrate available may be the cause of decline in power output. There were two major colonies formed on nutrient agar upon isolation of bacteria from anode, and only one colony was inoculated into the soil sample for study of electricity generation by pure culture, due to the survival of the colony on petri dish for more than two days.

Both pure culture and mixed culture have been successfully inoculated inside MFC for successful production of current. Despite, the amount of electricity generated when mixed culture was utilised significantly differ as opposed to pure culture. Mixed culture generally produced more electricity than pure culture, due to complex syntrophic relationship between the microorganism species in the MFC. Individual bacterial species in mixed culture was assumed to have specific mechanism in transferring electrons to produce high electricity generation, but the complex relationship has yet to be explained scientifically [1, 19]. Hence, in this experiment mixed culture MFC was able to produce slightly higher power output compared to pure culture MFC, agreeing claims from literature.

Some of pure bacterial species typically studied in MFC research were Geobacter sp., Shewanella sp., and Rhodoferax sp.. Pure exoelectrogenic species require longer time for growth in the chamber, a characteristic attributed to the anaerobic condition of the anode chamber. On the other hand, mixed culture usually grows faster, and is able to produce higher power output for the MFCs. Mixed culture is preferred as inoculum in MFC, but using mixed culture increase the startup time and longer time is required to reach stability of the power generated by the fuel cell. Furthermore, handling mixed culture is more challenging than pure culture. The difference in startup time of MFC with mixed and pure culture could be seen from Fig. 4, at which MFC with mixed culture light up after four days of inoculation, while pure culture MFC only took two days for the LED to be blinked. Additionally, mixed culture MFC required longer time (i.e. 17 days) to reach steady power output as opposed to pure culture MFC (i.e. 14 days).

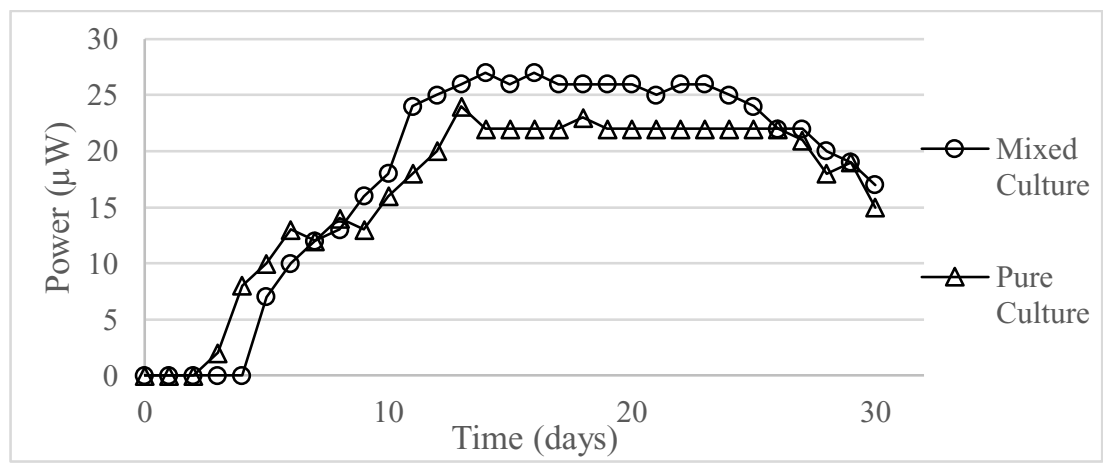

Fig. 4. Power generation in MFC by mixed and pure culture for 30 days. 


\subsection{Maximum power and current output}

The production of current (I) and voltage(V) from both MFC supplied with mixed and pure culture, linked with resistors of different values, and the maximum power and current output for mixed bacterial species were $77.62 \mu \mathrm{W}$ and $0.70 \mathrm{~mA}$, respectively. While for pure culture, the maximum power and current output were $51.32 \mu \mathrm{W}$ and $0.28 \mathrm{~mA}$, respectively.

\section{Conclusions}

In this research, the ability of bacteria isolated from rice paddy field soil to produce electricity calculated in power and current production was studied. Single chamber MFC provided with rice paddy field soil and the microbial consortia found in the soil generates $77.62 \mu \mathrm{W}$ of power and $0.70 \mathrm{~mA}$ of current. Pure exoelectrogenic bacteria isolated from the same microbiota generated maximum power of $51.32 \mu \mathrm{W}$ and $0.28 \mathrm{~mA}$. The maximum power and current could be achieved only when external resistance was equal to the internal resistance, and each MFCs (i.e. mixed culture and pure culture MFC) gave out different resistance values, with mixed culture MFC at $470 \Omega$ and pure culture MFC at $2200 \Omega$.

Growth of unknown bacteria was observed, and the bacteria reached the exponential phase of growth on the first day of inoculation, and the doubling time was calculated to be at 2.9 hours (173.3 minutes). Knowledge on the growth phase of the bacteria helped in deciding the exact time for inoculation of bacteria into rice paddy field soil for electricity generation by the pure culture MFC. Though the research was done in small scale, but this research act as a basis for the implementation of MFC device in actual rice paddy field in the future.

\section{References}

1. K. Rabaey, W. Verstraete. Trends Biotechnol 23, 291-8 (2005)

2. B.E. Logan, B. Hamelers, R.A. Rozendal, U. Schrorder, J. Keller, S. Freguia, et al., ES \& T 40, 5181-92 (2006)

3. M. Rahimnejad, A. Adhami, S. Darvari, A. Zirepour, S-E Oh, AEJ 54, 745-56 (2015)

4. D.R Lovley, Nature Rev. Microbiol. 4, 497-508 (2006)

5. I.S. Chang, H. Moon, O. Bretschger, J.K Jang, H.I Park, K.H Nealson, et al., J. Microbiol. Biotech. 16, 163-77 (2006)

6. B.E. Rittmann, R. Krajmalnik-Brown, R.U. Halden, Nature Rev. Microbiol. 6, 604-12 (2008)

7. B.E. Logan, Nature Rev. Microbiol. 7, 375-81 (2009)

8. N. Kaku, N. Yonezawa, Y. Kodama, K. Watanabe, Appl. Microbiol. Biotechnol. 79, 43-9 (2008)

9. S. Yamamoto, K. Suzuki, Y. Araki, H. Mochihara, T. Hosokawa, H. Kubota, et al., JSME 29, 145-53 (2014)

10. D.D. Deng, Y.C. Zhang, Y. Liu, RSC Adv. 5, 43978-89 (2015)

11. S. Viulu, K. Nakamura, A. Kojima, Y. Yoshiyasu, S. Saitou, K. Takamizawa, J. Gen. Appl. Microbiol. 59, 325-34 (2013)

12. A. Kouzuma, T. Kasai, G. Nakagawa, A. Yamamuro, T. Abe, K. Watanabe, Plos One, 8 (2013)

13. D. Datta, Principles and practices of rice production, (Int. Rice Res., 1981)

14. N. Wang, Z. Chen, H.B Li, J.Q. Su, F. Zhao, Y.G. Zhu, J. Soils Sediments 15, 926-36 (2015) 
15. R. Shuab, R. Lone, J. Naidu, V. Sharma, S. Imtiyaz, K.K. Koul, JAES 14, 527-35 (2014)

16. U.C. Brinch, F. Ekelund, C.S. Jacobsen, Appl. Environ. Microbiol. 68, 1808-16 (2002)

17. P.M. Steubing, Tested studies for laboratory teaching, 14, 81-114 (1993)

18. J.A. Myers, B.S. Curtis, W.R. Curtis, BMC Biophys. 6 (2013)

19. Y. Zuo, D.F. Xing, J.M. Regan, B.E. Logan, Appl. Environ. Microbiol. 74, 3130-7 (2008) 